\title{
CRIMSONpublishers
}

http://www.crimsonpublishers.com

Case Report

Surg Med Open Acc J

ఠ

ISSN 2578-0379

\section{Renal Tumor with Pancreatic Metastasis: About a Case Report}

\author{
Chaker Kays*, Sellami Ahmed, Ouanes Yassine, Essid Mohamed Ali, Abid Karem, Ben Rhouma Sami and Nouira \\ Yassine \\ Department of Urology, La Rabta Hospital, Tunisia
}

*Corresponding author: ChakerKays, Department of Urology, La Rabta Hospital

Submission: 眥 November 13, 2017; Published: 眥 December 04, 2017

\begin{abstract}
Metastatic lesions of the pancreas are rare and account for less than $2 \%$ of all pancreatic malignancies. Renal cell carcinoma is most commonly responsible for pancreatic metastasis. Meanwhile, the pancreas is an uncommon site of renal cell carcinoma metastasis. We report the case of a patient presented with renal tumor associated to synchronous pancreatic metastasis at the Urology department in the Rabta Hospital, who underwent a radical nephrectomy followed by immunotherapy. We will specify through a review of the literature the epidemiological, clinical, prognostic and therapeutic effects of pancreatic metastases of renal cancer.
\end{abstract}

Keywords: Renal tumor; Pancreatic metastasis; Immunotherapy; Radical nephrectomy

\section{Introduction}

Renal adenocarcinoma is an epithelial malignant tumor. Usual localizations of metastases are pulmonary, osseous and hepatic. Pancreatic metastases are exceptional and may occur late.

\section{Clinical Observation}

A 53-year-old patient, without urological or medical history, presented with epigastric pain lasting for 6 months. Physical examination and biology were normal. An abdominal scan showed a left renal lesion measuring $11 \mathrm{~cm}$, isodense with heterogeneous enhancing after injection of contrast material, associated to a pancreatic tissular lesion with a cystic central component (Figure 1). A pancreatic biopsy concluded to pancreatic metastasis of a probable renal cell carcinoma (Figure 2). The patient underwent a left radical nephrectomy approached by lumbotomy. The final histological examination concluded to renal cell adenocarcinoma Führman grade 2 (Figure 3). The patient was then addressed foranti-angiogenic treatment.

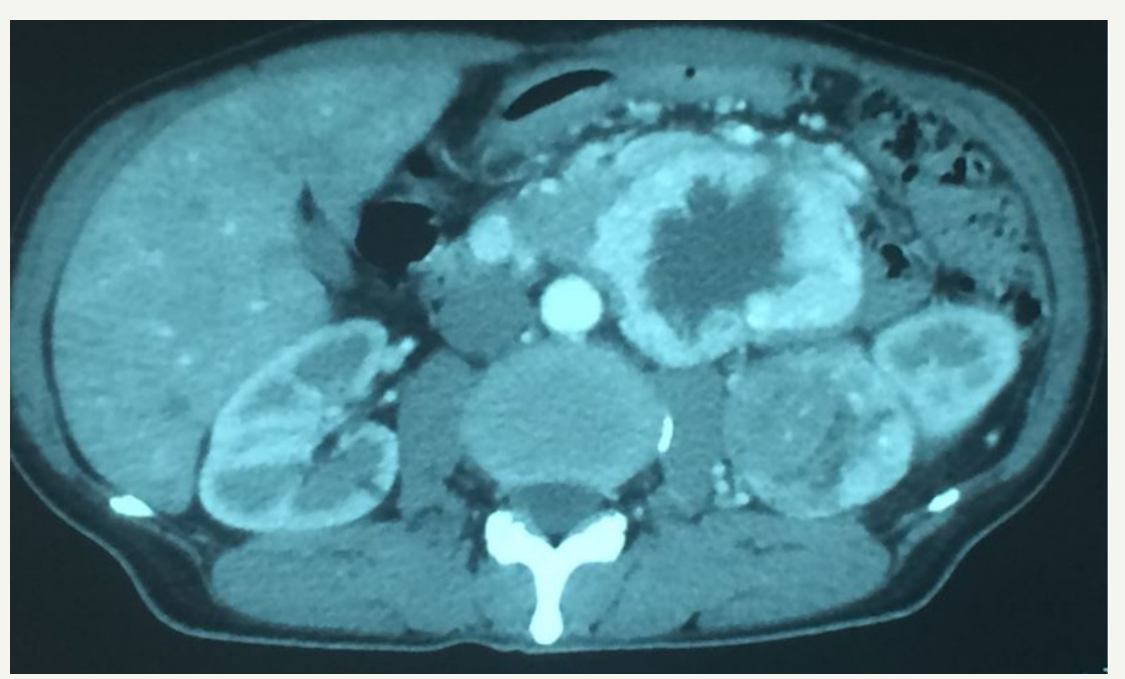

Figure 1: Abdominal CT scan showing a left renal lesion of $11 \mathrm{~cm}$, isodense with heterogeneous enhancing associated to a pancreatic tissular lesion with a cystic central component. 


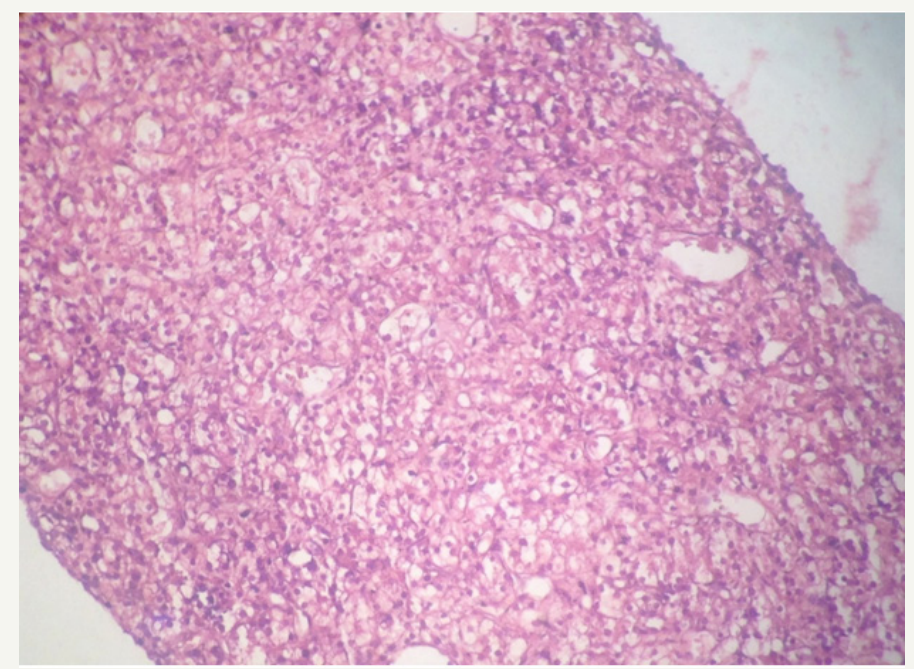

Figure 2: Pancreatic biopsy showing a pancreatic parenchyma infiltrated with epithelial cells suspecting a pancreatic metastasis of a renal cell carcinoma.

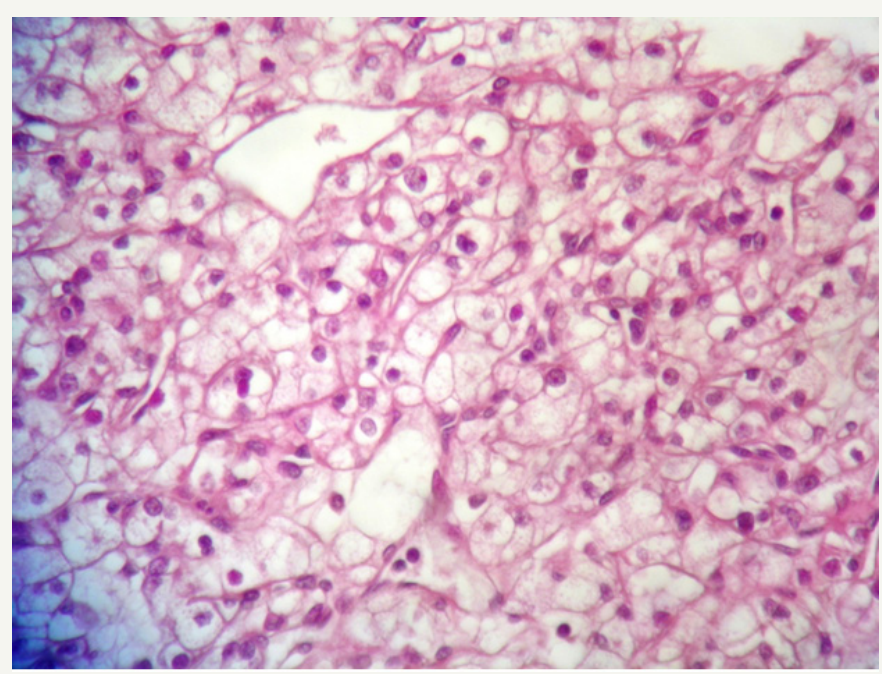

Figure 3: Histological examination concluding to clear renal cell adenocarcinoma Führman grade 2 with maximum diameter of $9 \mathrm{~cm}$, there was no invasion of the renal capsule. Pathological staging was T2a, Nx, M1.

\section{Discussion}

Pancreatic metastases excluding contiguous lesions are rare estimated at $3 \%$ of all pancreatic neoplasia [1]. Pancreatic metastasis of renal cancers can reveal the disease, but is most commonly metachronous with an average delay of 12 years, reaching extremes of 25 years [1]. These pancreatic lesions are asymptomatic in $50 \%$ of cases or evolve in a polymetastatic context: hepatic (20\%), pulmonary (20\%) or renal (12\%) [1], a finding confirmed by SAITOH's autopsy work shows that the rate of pancreatic metastases increases with the total number of secondary sites [2]. When pancreatic lesions are symptomatic, clinical signs are dominated by epigastric pain with frequent and important alteration of the general state [1]. The diagnosis is made by an abdominal and pelvic CT scan to certify the presence of a pancreatic lesion. Important vascularisation of the lesion shows it's renal origin that must be more suspected if the renal tumor is known [1]. In fact, only histological examination can confirm the diagnosis. It can be performed by guided biopsy which has a major risk of hemorrhage due to the hyper-vascularization of the lesion. Medical treatment of these metastatic lesions (hormonal, chemotherapy) is not effective but immunotherapy (Interferon, interleukin) seems to be the best therapeutic option [3]. Survival without recurrence at 2 years was $60 \%$ [4]. Overall survival at 2 years and 4 years is respectively $79 \%$ and $72 \%$ [4]. There is no significant difference between the overall survival of patients with multiple and unique pancreatic metastases [4]. The indications for surgical excision are based on data from the literature which show an acceptable survival after surgery. It therefore seems reasonable to limit the pancreatic surgery to patients with only a single synchronous or metachronepancreatic location [5].

\section{Conclusion}

Pancreatic metastasis of renal carcinoma remains rare. Literature data remains limited on this subject. Surgical treatment 
can be justified when the lesions, synchronous or metachronous, are limited to the pancreas in patients maintaining a good clinical condition

\section{References}

1. Avisse C, Flament JB, Deville J, Patey M, Brandt B, Marcus C (1995) Métastases endocriniennes multiples et tardives d'un adénocarcinome du rein. Multiple and late endocrine metastases of renal adenocarcinoma. Surgery Chirurgie 121: 50-53.

2. Saitoh H (1982) Distant metastasis of renal adenocarcinoma in nephrectomised cases. J Urol 127(6): 1092-1095.
3. Ramsay J (1992) Immunotherapy and chemotherapy for renal carcinoma of the kidney. Brit J Urol 70: 465-468.

4. Benhaima R, Mouracade P, Oussoultzoglou E, Jacqmina D, Bachellier P, et al. (0 Métastases pancréatiques des cancers du rein : intérêt d'une attitude agressive sur la survie des patients. Progrès en Urologie. Pancreatic metastasis of kidney cancers: interest of an aggressive attitude on the survival of patients, Progress in Urology 23(13): 1044.

5. Fabre JM, Rouanet P, Dagues F, Blanc F, Baumel H, et al. (1995) Various features and surgical approach of solitary pancreatic metastasis from renal cell carcinoma. Eur J Surg Oncol 21(6): 683-686. 